\title{
The Effects of Social Support and Communication with Parents on Eating Attitude of Nursing College Students
}

\section{간호대학생의 사회적 지지 및 부모와의 의사소통이 섭식태도에 미치는 영향}

Eun-Kyoung Han ${ }^{1}$, Young-Sun Park ${ }^{2}$, Yu-Jin Suh ${ }^{3 *}$

한은경 ${ }^{1}$, 박영선 ${ }^{2}$, 서유진 ${ }^{3}$

${ }^{1}$ Assistant Professor, College of Nursing, Eulji University, Seongnam, Korea, haahaa21@hanmail.net

${ }^{2}$ Associate Professor, College of Nursing, Kyungbok University, Namyangju, Korea, yspark@kbu.ac.kr

${ }^{3}$ Assistant Professor, College of Nursing, Dong-Eui University, Busan, Korea, yugibabe@naver.com

Corresponding author: Yu-Jin Suh

\begin{abstract}
The purpose of this study is to identify the effects of social support and communication with parents on eating attitude of nursing college students. Data were collected from April 23 to September 15,2018 , self-questionnaires from nursing college students. The collected data were analyzed using ttest, one way ANOVA, Pearson's correlation coefficient, and multiple linear regression analysis. In this study, it was found that the more depressed the mood state $(\beta=.35, \mathrm{p}<.001)$ of nursing college students' eating attitude and the negative communication with the father $(\beta=-.30, p<.001)$, the higher the abnormal eating attitude. The variables accounted for $20.1 \%$ of abnormal eating attitude. Based on the results of this study, a screening test for depression is necessary in order to detect nursing college students with early abnormal eating attitudes and postitive communication with the father will improve the abnormal eating attitude.
\end{abstract}

Keywords: Eating Attitude, Social Support, Communication with Parents, Nursing Students

요약: 본 연구는 간호대학생의 사회적 지지, 부모와의 의사소통이 섭식태도에 미치는 영향 요인을 확인하기 위함이다. 본 연구의 자료수집은 2018년 4월 23일부터 9월 1일까지 자가보고식 설문조사방법으로 시행되었다. 수집된 자료의 분석은 t-test, one-way ANOVA, 상관관계 분석, 다중선형회귀분석으로 실시하였다. 연구결과 우울한 기분( $\beta=.35, \mathrm{p}<.001)$, 아버지와의 부정적 의사소통 $(\beta=-.30, \mathrm{p}<.001)$ 이 간호대학생의 이상 섭식태도에 유의한 영 향을 미치는 변수로 나타났고, 이 변수들의 설명력은 $20.1 \%$ 로 나타났다. 본 연구결과를 바탕으로 이상섭식 태도를 가진 간호대학생을 조기에 발견하기 위해서 우울증 선별검사 가 필요하며, 아버지와의 긍정적 의사소통이 이상섭식태도의 개선에 도움이 될것으로 사료된다.

핵심어: 섭식태도, 사회적 지지, 부모와의 의사소통, 간호대학생

Received: December 26, 2020; $1^{\text {st }}$ Review Result: February 5, 2021; $2^{\text {nd }}$ Review Result: March 31, 2021 Accepted: April 30, 2021 


\section{1. 서론}

최근 들어 다양한 미디어매체에서는 마른 몸매를 과도하게 긍정적으로 평가하는 방송 을 흔히 볼 수 있다. 이와 같은 대중매체의 전달은 아직 가치관 확립이 완성되지 않은 대학생에게 신체외모를 비교하게 되면서 마른 체형을 갖기 위하여 의도적으로 섭식을 조 절한다. 미국 정신의학회의 Diagnostic and Statistical Manual of Mental Disorder-5 (DSM-5)에서 는 섭식장애(Eating disorder)를 장시간 계속되는 섭식의 장애로, 개인의 신체 또는 정신 건 강을 심각하게 손상시키는 정신장애로 정의하고 있다[1]. 섭식장애로 진단받은 환자는 2008년에 10,940 명에서 2012년에는 13,002명으로 5년간 약 $18.8 \%$ 가 급증하였다[2]. Nakai, $\mathrm{Nin}, \& \mathrm{Noma}[3]$ 연구에서는 과체중에 대한 잘못된 인식과 과도한 다이어트로 인하여 아시 아 국가 대학생들에게 섭식장애가 나타나는 것으로 보고되었다. 섭식장애는 우울, 불안, 대인관계 기피증과 같은 정신 질환뿐만 아니라 골다공증, 소화장애, 심장마비 등 주요 장 기손상을 초래하기 때문에 사망률이 높은 정신질환이다[4]. 섭식장애는 특히 젊은 여성에 서 발병률이 높고, 한번 발병되면 만성적인 특성을 보인다[5]. 청소년기에서 청년기로 전 환이 되는 대학생 시기는 건강과 질병예방을 위한 중요한 생활습관을 들여야 하지만 우 리나라 대학생은 부모의 관심에서 벗어난 대학생은 건강증진행위가 감소되며 특히 불규 칙적인 식습관으로 건강에 문제가 발생한다. 이에 대학생의 섭식태도와 관련된 요인을 확인하여 문제를 조기에 예방하고 중재를 통해 건강한 생활을 유지할 수 있도록 도와야 한다.

지금까지 연구된 섭식태도와 관련된 요인은 체질량 지수, 체형인식[6][7], 자아탄력성, 대인관계, 우울, 자아 존중감[6-9], 가족구조와 기능[10], 부모양육 태도[9]로 나타났다. 이 처럼 섭식태도와 관련된 요인은 신체적, 심리적, 가족적 요인으로 조사되었다. 이 가운데 부모와 자녀 관계는 인간 성장발달에 가장 기본적이면서 중요한 요인이다. Kim과 Yang [11]은 중학생을 대상으로 부모-자녀 의사소통 유형이 개방형일 때 섭식장애정도가 감소 되고 폐쇄형 의사소통일 때 섭식장애정도가 증가한다고 하였다. 하지만 자녀가 인지하는 부모 각각에 대한 의사소통 정도를 확인하지 못했다. 또한 긍정적인 변수인 사회적 지지 는 한 개인이 대인관계에서 신뢰와 위로의 경험을 통해 얻을 수 있는 긍정적 자원을 말 하며 이러한 지지를 받은 경우에는 더 나은 신체적 건강과 심리적 안녕을 보이게 되므 로, 사회적 지지는 중재 자원이자 보호요인이 된다[12]. 대학생은 독립된 인격체로서 사회 구성원이 되어가는 사회인으로서, 사회적 지지는 개인의 인생과 정신건강의 여러 변화에 대한 적응에 긍정적인 영향을 미친다. 따라서 사회적 지지는 정신건강의 다양한 변화나 스트레스를 감소시키는 요인으로 작용하므로[13] 섭식태도애 영항을 미칠 수 있을 것으로 예측된다. 하지만 지금까지 이루어진 섭식태도 연구에서는 자녀가 인지하는 부모 각각에 대한 의사소통 정도를 확인하지 못하였고, 긍정적 변수인 사회적 지지를 포함시켜 섭식 태도에 영향을 주는지 규명한 연구는 부족한 실정이다.

따라서 본 연구의 목적은 간호대학생을 대상으로 사회적 지지, 부모와의 의사소통이 섭식태도에 미치는 영향요인을 확인함으로써, 간호대학생의 섭식태도를 향상시킬 수 있 는 기초자료를 제공하기 위함이다. 이를 위한 구체적인 목적은 다음과 같다. 1) 간호대학 생의 일반적 특성, 사회적 지지, 부모와의 의사소통 및 섭식태도 정도를 파악한다. 2) 간 호대학생의 일반적 특성에 따른 섭식태도의 차이를 파악한다. 3) 간호대학생의 사회적 지 
지, 부모와의 의사소통 및 섭식태도와의 관계를 파악한다. 4) 간호대학생의 섭식태도에 미 치는 영향요인을 파악한다.

\section{2. 연구방법}

\section{1 연구설계}

본 연구는 간호대학생의 사회적 지지, 부모와의 의사소통 및 섭식태도 정도를 파악하고 사회적 지지와 부모와의 의사소통이 섭식태도에 미치는 영향요인을 규명하기 위한 서술적 조사연구이다.

\section{2 연구대상}

본 연구의 대상자는 경기도 및 광주광역시 소재 2 개 4 년제 대학교에 재학 중인 간호대학생을 대상으로 편의표집하였다. 본 연구에서 필요한 대상자의 수는 G power 3.1.1 analysis software 를 이용하여 다중회귀분석에 필요한 표본수를 산출하였다. Lee \& Kim 의[14] 연구를 근거로 연구유의수준 .05, 검정력 .80 , 중간효과크기. 15 , 예측변수 14 개를 기준 으로 최소 표본 수는 135 명이 권고되었으나, 탈락률을 고려하여 170 명을 대상으로 실시 하였다. 회수된 설문지 가운데 응답이 설문문항에 응답하지 않은 8 부를 제외한 총 162 부를 최종 분석하였다.

\section{3 자료수집 방법 및 윤리적 고려}

본 연구를 위한 자료수집 기간은 2018년 4월 23일부터 9월 15 일에 이루어졌다. 연구 참여자에게 연구목적과 방법을 설명하고 연구참여에 동의한 대상자에 한에서 실시하였 다. 구조화된 설문지로 자료를 수집하였으며 연구대상자의 윤리를 고려하여 연구의 익명 성과 비밀보장이 됨을 설명하였고, 개인을 식별할 수 있는 정보가 절대 노출되지 않을 것과 연구 이외에는 사용되지 않음을 설명하였다. 또한 연구에 참여하지 않음으로 인하 여 불이익이 없음을 설명하였고 연구 참여 도중 언제든지 철회할 수 있음을 미리 설명 하였다. 설문지 작성에 소요된 시간은 약 10 분 정도이었고, 설문을 완성한 학생에게는 소정의 문구제품을 제공하였다.

\section{4 연구도구}

\subsection{1 일반적 특성}

일반적 특성은 성별, 나이, 거주형태, 음주여부, 카페인 음료섭취 여부, 운동여부, 학업 만족도, 스트레스 정도, 건강상태, 기분상태 등을 포함하여 총 10 문항이었다.

\subsection{2 사회적 지지}

사회적 지지는 $\operatorname{Park[15]ㅇㅣ~ㄱㅐㅂㅏㄹㅎㅏㄱㅗ,~Hwang[16]ㅇㅣ~ㅅㅜㅈㅓㅇㅎㅏㅇㅕ~ㅍㅛㅈㅜㄴㅎㅘㅎㅏㄴ~ㅊㅓㄱㄷㅗㄹㅡㄹ~}$ 사용하였다. 총 25 개 문항으로 구성되었으며, 각 문항은 5점 리커트 척도로 점수가 높을수록 사회적 지지가 높음을 의미한다. Hwang[16] 연구에서 Cronbach's alpha= .93이었으며, 
본 연구에서 Cronbach's alpha $=.96$ 이었다.

\subsection{3 부모-자녀 의사소통 척도}

부모-자녀 의사소통은 Barnes와 Olson[17]의 부모-자녀 간의 의사소통 척도(Parent Adolescent Communication Inventory: $\mathrm{PACI}$ 를 $\mathrm{Min}[18]$ 이 수정한 척도를 사용하였다. 총 20개 문항으로 구성되었으며, 각 문항은 5점 리커트 척도로 점수가 높을수록 긍정적인 측면을 의미한다. 도구 개발당시 부모-자녀 의사소통척도의 Cronbach's alpha $=90$ 이었으며, 본 연구 에서 Cronbach's alpha $=.94$ 이었다.

\subsection{4 섭식태도}

섭식태도는 Garner, Olmsted, Bohr와 Garfinkel[19]가 개발한 단축형 섭식태로 측정도구(The Eating Attitude Test-26, EAT-26)를 Choi, Ahn, Nam, Cho와 Choi[20]가 번안한 척도를 사용하였다. 본 측정도구는 총 26개 문항이며 6점 리커트 척도로 구성되어 있으나 '가끔 그렇다', '거의 그렇지 않다', '전혀 그렇지 않다'는 0점, '자주 그렇다' 는 1점, '매우 자주 그렇다' 는 2점, '항상 그렇다'는 3점으로 계산한다. 문항의 총점이 20점 이상일 때 신경성 식욕 부진증과 신경성 폭식증 등 이상섭식태도를 의미한다. 도구 개발당시 신뢰도는 Cronbach's alpha $=.79$ 였고 본 연구에서 도구의 Cronbach's alpha $=.82$ 이었다.

\section{5 자료분석방법}

본 연구의 자료는 SPSS/WIN 22.0 프로그램을 이용하여 분석하였다. 대상자의 일반적 특성은 빈도와 백분율을 구하였고, 일반적 특성에 따른 섭식태도의 차이는 t-test, one way ANOVA, 사후 검정은 Schéff test 를 실시하였다. 부모와의 의사소통, 사회적 지지와 부모 와의 의사소통 의 관계는 Pearson's correlation coefficient로 분석하였다. 섭식태도에 미치는 영향요인을 파악하기 위해 다중선형회귀분석(Multiple linear regression analysis)를 시행하 였다.

\section{3. 결과}

\section{1 대상자의 일반적 특성에 따른 섭식태도의 차이}

본 연구 대상자의 성별은 여학생이 135 명(83.3\%)이었으며, 평균연령은 $22.32 \pm 2.08$ 세 이었다. 음주를 하는 학생이 105 명(64.8\%), 카페인 음료를 섭취하는 학생이 130 명 $(80.2 \%)$ 이었으며, 운동을 하지 않는 학생은 103 명(63.6\%)이었다. 자신의 건강상태에 대해 '건강 하다' 는 58 명(35.8\%)으로 가장 높았으며 기분상태는 '우울하다' 는 51 명(31.5\%), '보 통이다' 는 46 명(28.4\%), '좋다' 는 41 명 (25.4\%), '매우 우울하다' 는 12 명 $(7.4 \%)$ 으로 나타났다. 대상자의 일반적 특성에 따른 섭식태도의 차이는 스트레스 $(\mathrm{F}=5.55, \mathrm{p}<.001)$, 우울 $(\mathrm{F}=9.15, \mathrm{p}<.001)$ 에서 통계적으로 유의한 차이가 나타났다. 사후검정결과 스트레스가

'매우 높음' 이라고 응답한 집단이 스트레스가 '높음', '보통' 인 집단보다 섭식태 도가 유의하게 높았다. 또한 기분상태에서는 '우울하다' 라고 응답한 집단이 '기분이 
좋다, 라고 응답한 집단보다 섭식태도 점수가 유의하게 높았다. 사후검정 결과 학업 만족도와 건강상태는 유의한 차이가 나타나지 않았다 [Table 1].

\section{2 대상자의 사회적 지지, 부모와의 의사소통, 섭식태도 정도}

본 연구 대상자의 사회적 지지는 점수 범위가 25 125점으로 평균 97.01점이었다. 아버지/어머니와의 의사소통의 점수범위는 $10 \sim 50$ 점으로 아버지와의 의사소통 점수는 평 균 30.63점이었고 어머니와의 의사소통은 평균 40.88점이었다. 섭식태도의 점수범위는 0 34점이고 평균 9.33점이었다[Table 2].

[표 1] 대상자의 일반적 특성표 $(\mathrm{N}=162)$

[Table1] General Characterisitcs of the Participants $(\mathrm{N}=162)$

\begin{tabular}{|c|c|c|c|c|}
\hline Variables & Categories & $\begin{array}{l}\mathrm{N}(\%) \\
\mathrm{M} \pm \mathrm{SD}\end{array}$ & $\begin{array}{c}\text { Eating attitides } \\
\mathrm{M} \pm \mathrm{SD}\end{array}$ & $\begin{array}{c}\text { F or t } \\
\text { (p) }\end{array}$ \\
\hline Gender & $\begin{array}{l}\text { Male } \\
\text { Female }\end{array}$ & $\begin{array}{c}27(16.7) \\
135(83.3)\end{array}$ & $\begin{array}{l}7.78 \pm 7.33 \\
9.64 \pm 7.94\end{array}$ & $\begin{array}{l}-1.08 \\
(.281)\end{array}$ \\
\hline Age & $\begin{array}{c}21 \\
22 \\
\geq 23\end{array}$ & $\begin{array}{l}60(37.0) \\
64(39.5) \\
38(23.5)\end{array}$ & $\begin{array}{c}9.93 \pm 6.16 \\
10.06 \pm 9.59 \\
7.16 \pm 8.26\end{array}$ & $\begin{array}{l}1.771 \\
(.173)\end{array}$ \\
\hline Residence type & $\begin{array}{c}\text { Home } \\
\text { Loding House } \\
\text { Dormitory }\end{array}$ & $\begin{array}{l}80(49.4) \\
58(35.8) \\
24(14.8)\end{array}$ & $\begin{array}{c}8.67 \pm 8.05 \\
8.76 \pm 6.99 \\
12.92 \pm 10.47\end{array}$ & $\begin{array}{l}2.756 \\
(.067)\end{array}$ \\
\hline Drinking & $\begin{array}{l}\text { No } \\
\text { Yes }\end{array}$ & $\begin{array}{c}57(35.2) \\
105(64.8)\end{array}$ & $\begin{array}{l}9.95 \pm 9.64 \\
9.00 \pm 7.31\end{array}$ & $\begin{array}{l}.702 \\
(.484)\end{array}$ \\
\hline Caffeine intake & $\begin{array}{l}\text { No } \\
\text { Yes } \\
\end{array}$ & $\begin{array}{c}32(19.8) \\
130(80.2)\end{array}$ & $\begin{array}{l}9.24 \pm 7.84 \\
9.72 \pm 9.62\end{array}$ & $\begin{array}{l}-.296 \\
(.767) \\
\end{array}$ \\
\hline Exercise & $\begin{array}{l}\text { No } \\
\text { Yes }\end{array}$ & $\begin{array}{c}103(63.6) \\
59(36.4)\end{array}$ & $\begin{array}{c}8.82 \pm 8.05 \\
10.24 \pm 8.43\end{array}$ & $\begin{array}{r}-1.063 \\
(.289)\end{array}$ \\
\hline Academic satisfaction & $\begin{array}{c}\text { Dissatisfaction } \\
\text { Moderate } \\
\text { Satisfaction }\end{array}$ & $\begin{array}{l}42(25.9) \\
54(33.3) \\
66(40.7)\end{array}$ & $\begin{array}{c}10.23 \pm 8.13 \\
9.03 \pm 8.95 \\
9.00 \pm 7.65\end{array}$ & $\begin{array}{c}.343 \\
(.710)\end{array}$ \\
\hline Stress & $\begin{array}{c}\text { Low }^{\mathrm{a}} \\
\text { Moderate }^{\mathrm{b}} \\
\text { High }^{\mathrm{c}} \\
\text { Very Hig }^{\mathrm{d}}\end{array}$ & $\begin{array}{c}14(8.6) \\
24(14.8) \\
86(56.1) \\
38(23.5)\end{array}$ & $\begin{array}{c}10.29 \pm 7.03 \\
6.42 \pm 5.01 \\
8.12 \pm 8.58 \\
13.58 \pm 7.88\end{array}$ & $\begin{array}{l}5.545 \\
(<.001) \\
d>c>b\end{array}$ \\
\hline Health state & $\begin{array}{c}\text { Poor } \\
\text { Moderate } \\
\text { Good } \\
\text { Vey Good }\end{array}$ & $\begin{array}{l}30(18.5) \\
45(27.8) \\
58(35.8) \\
29(17.9)\end{array}$ & $\begin{array}{c}9.01 \pm 8.68 \\
10.96 \pm 8.39 \\
9.48 \pm 8.69 \\
6.79 \pm 5.67\end{array}$ & $\begin{array}{l}1.551 \\
(.204)\end{array}$ \\
\hline Mood status & $\begin{array}{c}\text { Good }^{\mathrm{a}} \\
\text { Normal }^{\mathrm{b}} \\
\text { Depressed }^{\mathrm{c}}\end{array}$ & $\begin{array}{l}53 \\
46 \\
63\end{array}$ & $\begin{array}{c}6.06 \pm 5.59 \\
9.08 \pm 6.87 \\
12.27 \pm 9.78\end{array}$ & $\begin{array}{c}9.150 \\
(<.001) \\
\mathrm{c}>\mathrm{a}\end{array}$ \\
\hline
\end{tabular}

$\dagger$ Scheffé test 


\section{3 대상자의 사회적 지지, 부모와의 의사소통, 섭식태도와의 관계}

본 연구 대상자의 섭식태도는 아버지와의 의사소통 $(\mathrm{r}=-.294, p<.001)$ 과 통계적으로 유 의한 양의 상관관계를 보였다. 즉 아버지와의 의사소통이 폐쇄적이고 부정적일수록 섭식 태도도 부정적이었다. 아버지와의 의사소통은 어머니와의 의사소통과 $(\mathrm{r}=.366, p<.001)$ 통계 적으로 유의한 양의 상관관계를 보였다. 어머니와의 의사소통 $(\mathrm{r}=.008, p=.922)$ 과 사회적 지지 $(\mathrm{r}=-.010, p=.897)$ 는 섭식태도와 유의한 상관관계가 나타나지 않았다 [Table 3].

[표 2] 대상자의 사회적 지지, 부모와의 의사소통, 섭식태도 정도

[Table 2] Degree of Social Support, Communication with Parent, Eating Attitude (N=162)

\begin{tabular}{|c|c|c|}
\hline Variables & M \pm SD & Range \\
\hline Social Support & $97.01 \pm 14.88$ & $25 \sim 125$ \\
\hline Communication with father & $30.63 \pm 9.75$ & $10 \sim 50$ \\
\hline Communication with mather & $40.88 \pm 7.71$ & $10 \sim 50$ \\
\hline Eating attitude & $9.33 \pm 8.19$ & $0 \sim 34$ \\
\hline
\end{tabular}

[표 3] 대상자의 사회적 지지, 부모와의 의사소통, 섭식태도와의 관계

[Table3] Correlations between Social Support, Communication with Parent, Eating Attitude $(\mathrm{N}=162)$

\begin{tabular}{|c|c|c|c|}
\hline \multirow{2}{*}{ Variables } & Eating attitude & Communication with father & Communication with mather \\
\hline & \multicolumn{3}{|c|}{$\mathbf{r}(\mathbf{p})$} \\
\hline Eating attitude & 1 & & \\
\hline Communication with father & $-.294(<.001)$ & 1 & \\
\hline Communication with mather & $.008(.922)$ & $.366(<.001)$ & 1 \\
\hline Social support & $-.010(.897)$ & $.302(<.001)$ & $.357(<.001)$ \\
\hline
\end{tabular}

\section{4 대상자의 섭식태도에 미치는 영향요인}

본 연구에서 섭식태도에 미치는 영향요인을 규명하기 위해서 일반적 특성에서 통계적으로 유의한 차이를 보였던 스트레스, 기분상태, 아버지와의 의사소통, 어머니와의 의사소통 및 사회적 지지를 더미변수로 하여 다중회귀분석을 시행하였다. 다중회귀분석 사용의 적절성을 검토하기 위하여 종속변수의 자기상관과 독립변수들간의 다중공선성을 확인하였다. 그 결과, Durbin-Watson 통계량은 1.81 로 기준값인 2 에 가까워 자기상관의 문제가 없었다. 독립변수간의 다중공정성은 공차한계와 분산팽창계수를 이용하여 확인 하였다. 그 결과 공차한계는 .791 .823 사이로 모두 0.1 이상이었고, 분산팽창계수는 1.216 -1.359으로 모두 10 미만으로 독립변수간의 다중공선성이 없는 것으로 나타나, 이 자료는 회귀분석을 실시하기에 적합하였다. 분석결과 섭식태도의 영향요인 회귀모형은 통계적 
으로 유의하였고 $(\mathrm{F}=6.724, \mathrm{p}<.001)$, 모형의 설명력은 $20.1 \%$ 이었다. 본 연구결과 대학생의 섭식태도에 영향을 미치는 요인은 기분상태 $(\beta=.35, \mathrm{p}<.001)$, 아버지와의 의사소통 ( $\beta=-.30$, $\mathrm{p}<.001)$ 으로 나타났다. 즉, 기분상태가 우울할수록, 아버지와의 의사소통이 부정적일수록 이상섭식태도가 높은 것으로 나타났다 [Table 4].

[표 4] 대상자의 섭식태도에 미치는 영향요인

[Table 4] Inflencing Factors on Eating Attitudes ( $\mathrm{N}=162)$

\begin{tabular}{|c|c|c|c|c|}
\hline \multirow{2}{*}{ Variables } & \multicolumn{4}{|c|}{ Model I } \\
\hline & B & SE & $\beta$ & $\mathbf{t}(p)$ \\
\hline (Constant) & 18.501 & 6.037 & & $3.064(<.001)$ \\
\hline Stress & 073 & .355 & .016 & $.205(.838)$ \\
\hline Mood status & 2.724 & 630 & .350 & $4.29(<.001)$ \\
\hline Social support & .033 & .044 & .059 & $.751(.454)$ \\
\hline Communication with father & -.255 & .066 & -.304 & $-3.857(<.001)$ \\
\hline Communication with mather & 070 & 087 & .067 & $.809(.420)$ \\
\hline $\mathrm{F}(\mathrm{p})$ & \multicolumn{4}{|c|}{$8.883(<.001)$} \\
\hline $\mathrm{R}^{2}$ & \multicolumn{4}{|c|}{.226} \\
\hline Adjusted $\mathrm{R}^{2}$ & \multicolumn{4}{|c|}{.201} \\
\hline Durbin-Watson & \multicolumn{4}{|c|}{1.810} \\
\hline
\end{tabular}

\section{4. 논의 및 결론}

본 연구는 간호대학생의 사회적 지지, 부모와의 의사소통, 섭식태도에 대한 수준과 각 변인들과의 관계를 파악하고 섭식태도에 어떤 영향을 미치는지 파악하고자 시도되었다. 본 연구에서 대상자의 일반적 특성과 섭식태도를 살펴보면, 스트레스와 기분상태가 섭식 태도에 통계적으로 유의하게 차이가 나타났다. 스트레스가 높을수록 섭식태도 점수가 높게 나타난 것과 기분상태가 우울할수록 섭식태도 점수가 높게 나타난 것은 대학생을 대상으로 시행한 Jang 과 $\mathrm{Kang}[21]$ 의 연구 결과를 지지하였다. Baek 등[22]의 연구에서도 우울한 경우가 이상섭식태도 발생확률을 5.47 배 증가시킨다고 하였다. 이처럼 우울, 스트레스와 같이 심리적 요인들이 섭식장애에 미치는 영향요인으로 일관되게 보고되고 있는 것으로 확인되었다. 이러한 결과를 통하여 간호대학생을 위한 우울선별 검사와 스트레스 관리 교육이 부정적 섭식태도를 예방하기 위해서 중요한 전략이 될 수 있을 것 으로 사료된다.

본 연구에서는 사회적 지지, 아버지와 어머니와의 의사소통 및 섭식태도와의 상관관계 룰 분석한 결과에서 아버지와의 의사소통이 섭식태도와 음의 상관관계를 보였고 어머니 와의 의사소통은 상관관계가 나타나지 않았다. 본 연구 결과는 의사소통이 폐쇄적이고 부정적일수록 이상섭식태도 점수가 높다는 $\mathrm{Kim}$ 과 $\mathrm{Yang}[11]$ 의 연구결과와 유사하다. 또한 청소년을 대상으로 한 선행연구에서 부모와의 의사소통이 잘 될수록 청소년의 식이태도 
에 긍정적인 영향을 준다는 연구결과[14]를 본 연구결과가 지지하고 있다. 이는 섭식태도 의 중요 변수로 아버지와의 의사소통 유형이 중요함을 시사하는 바이다. 이상섭식태도를 나타내는 간호대학생의 경우 특히, 아버지와의 의사소통 유형을 확인하여 아버지와 대화 의 기회를 마련하고, 개방적으로 의사소통을 함으로써 자유롭게 감정을 쉽게 표현하여 대화로 문제를 해결할 수 있는 지원체계가 필요하다. 이러한 부모-자녀간의 의사소통을 통하여 섭식태도에 긍정적인 영향을 줄 것이라고 사료된다.

간호대학생의 섭식태도에 영향요인을 살펴본 결과, 기분상태와 아버지와의 의사소통이 영향 요인으로 파악되었고, 전체 설명력은 $20.1 \%$ 로 나타났다. 간호대학생의 기분상태가 우울할수록, 아버지와의 의사소통이 부정적일수록 이상섭식태도가 나타나는 것으로 밝혀 졌다. 여대생을 대상으로 이상섭식행동의 영향요인을 조사한 선행연구에서도 우울은 강 력한 위험요인으로 보고되어[9] 본 연구결과를 지지한다. 우울한 기분은 자신감을 저하 시키고, 부정적 감정 표출을 회피하는 특성으로 인하여 섭식태도에 부정적으로 영향을 주는 매개변수의 역할을 한다고 하였다[23][24]. 이상섭식태도로 인하여 섭식장애가 나타 나고 이는 정신 질환뿐만 아니라 주요장기 손상을 초래할 수 있기 때문에 간과해서는 안된다. 따라서 이상섭식태도를 갖고 있는 간호대학생을 중재할 때에는 우울증 선별 검 사를 실시하여 우울증 여부를 먼저 확인해야 한다. 뿐만 아니라 대학생의 섭식장애 예방 프로그램을 개발시 심리적, 정서적 요인을 상담할 수 있는 교육 내용이 포함되어야 한다고 사료된다.

본 연구에서는 아버지와의 의사소통이 부정적일수록 이상섭식태도가 나타났는데 선행 연구에서 아버지와 어머니 각각에 대해 독립적으로 의사소통 정도를 파악한 연구가 부 족하여 직접적인 비교는 제한적이었다. 하지만 섭식장애가 있는 여성 환자와 일반인 여성을 대상으로 아버지의 양육태도를 조사한 선행연구에서 섭식장애 환자에서 아버지의 과잉보호 비율이 더 높았다. 아버지의 과잉보호는 섭식장애 환자의 음식 제한, 체형, 외 모 및 식사에 대한 걱정 수준을 더 높게 하는 것으로 보고되었다[25]. 이와 같이 아버 지의 과잉보호하는 양육태도가 섭식장애에 영향을 미쳐 아버지와의 의사소통이 부정적 일수록 섭식태도에 영향을 줄 수 있다고 간주할 수 있다. Kim과 $\mathrm{Yang}[11]$ 의 연구에서는 부모-자녀 의사소통이 원활할수록 섭식장애 정도가 감소되었고, 개방형 의사소통이 증가 할수록 섭식장애 정도가 감소하는 것으로 나타났다. 따라서 부모-자녀 간의 개방적인 대화를 나누고, 특히 아버지와의 의사소통시 억압을 느끼지 않고 자유롭게 상호작용을 할 수 있는 분위기를 조성하여 감정을 쉽게 표현해야 한다. 이러한 의사 소통을 통하여 갈등 발생시 대화로 문제를 해결하고, 일방적인 의사소통이 아니라 상호 작용을 통하여 의사소통을 하게 된다. 간호대학생의 학업, 친구와의 관계 및 진로에 대한 고민 등과 같이 대학생이 느낄 수 있는 심리적 어려움과 함께 섭식태도를 긍정적으로 향상시킬 수 있을 것으로 사료된다.

본 연구의 제한점은 다음과 같다. 첫째, 4년제 대학 두곳에서 표집했으나 일부 간호 대학생을 대상으로 조사하였기 때문에 연구결과를 일반화 시키기에는 제한적이다. 따라 서 연구 대상을 확대시켜 재검증하는 것이 필요하다. 둘째, 부모와의 의사소통 연구에서는 아버지와 어머니 각각을 독립적으로 분석한 연구들이 부족한 실정이다. 이에 부모와 자녀와의 의사소통 경험과 같은 질적연구를 통해 양적연구에게 측정하지 못한 부분을 심도깊게 파악할 수 있을 것이다. 셋째, 간호대학생의 섭식태도에 대해 밝혀지지 
않은 다양한 요인들을 규명하기 위한 반복 연구가 필요할 것으로 사료된다.

본 연구는 간호대학생의 섭식태도에 기분상태와 아버지와의 부정적 의사소통이 영향을 미치는 요인으로 확인되었다. 본 연구결과를 바탕으로 이상섭식태도가 나타나는 간호 대학생을 조기발견하기 위해서는 우울증 선별검사가 필요하고 이상섭식태도 예방 중재 프로그램 개발시 우울과 같은 부정적인 정서를 표현할 수 있는 전략적 요소가 필요하다. 또한, 간호대학생의 섭식장애에 아버지와의 부정적 의사소통이 예측요인으로 확인한 점 이 이 연구에서 갖는 의의로 여진다. 긍정적인 섭식태도를 갖기 위해서 부모와의 지지 체계와 의사소통 유형을 사정하고 폐쇄적인 의사소통을 줄이고 개방적인 의사소통을 통 하여 감정을 표현하고 자유롭게 상호작용을 할 수 있는 방법을 고안하는 것이 필요할 것으로 사료된다.

\section{References}

[1] American Psychiatry Association, Diagnostic and Statistical Manual of Mental Disorders (5th ed.), American Psychiatric Publishing, (2013)

[2] https://wwwhira.or.kr/re/stcIlnsInfm/stcIlnsInfmView.do?pgmid=HIRAA030502000000\&sortSno=162, Mar 21(2020)

[3] Y. Nakai, K. Nin, S. Noma, Eating Disorder Symptoms among Japanese Female Students in 1982, 1992 and 2002, Psychiatry Research, (2014), Vol.219, No.1, pp.151-156, https://doi.org/10.1016/j.psychres.2014.05.018

[4] K. Bühren, R. Schwarte, F. Fluck, N. Timmesfeld, M. Krei, K. Egberts, E. Pfeiffer, C. Fleischhaker, C. Wewetzer, B. H. Dahlmann, Comorbid Psychiatric Disorders in Female Adolescents with first onset anorexia nervosa, European Eating Disorders Review, (2014), Vol.22, No.1, pp.39-44, https://doi.org/10.1002/erv.2254

[5] Y. S. Kim, S. S. Kong, Original Articles : A Study on Weight-Control Behaviors, Eating Disorder Symptoms and Depression among Female Adolescents, Journal of Korean Academic Psycho Mental Health Nursing, (2004), Vol.13, No.3, pp.304-314.

[6] B. Mayer, P. Muris, C. Meesters, R. Zimmermann-van Beuningen, Brief Report: Direct and Indirect Relations of Risk Factors with Eating Behavior Problems in Late Adolescent Females, Journal of Adolescence, (2009), Vol.32, No.3, pp.741-746, https://doi.org/10.1016/j.adolescence.2008.12.002

[7] Y. Yom, K. E. Lee. Factors Affecting Eating Attitude of Female Undergraduates in Regard to BMI, Journal of Korean Academy of Nursing, (2010), Vol.40, No.5, pp.676-685, https://doi.org/10.4040/jkan.2010.40.5.676

[8] H. K. Chang, J. N. Sohn, Influence of Appearance Stress, Ego - Resilience, Interpersonal Relations and Depression on Eating Attitude in Women Undergraduates, Journal of Korean Academy of Fundamentals of Nursing, (2014), Vol.21, No.3, pp.235-242, https://doi.org/10.7739/jkafn.2014.21.3.235

[9] Y. Choi, S. Kim, Factors associated with Abnormal Eating Behaviors among Women College Students, Journal of Korean Academy of Psychiatric and Mental Health Nursing, (2017), Vol.26, No.2, pp.134-142.

[10] J. Y. Park, S. Y. Baek, H. S. Kim, J. H. Lim, T. H. Kim, Testing the Biobehavioral Family Model in Understanding the Eating Problems of Adolescent Girls, Child Health Nursing Research, (2013), Vol.19, No.3, pp.228-237

[11] K. Kim, K.Yang, The Relationship between Eating Disorders and Parent-Adolescent Communication in Middle School Students in Rural Areas, Journal of Korean Academy of Nursing, (2008), Vol.38, No.1, pp.55-63

[12] S. Cohen, T. A. Wills, Stress, social support, and the buffering hypothesis, Psychological bulletin, (1985), Vol.98, No.2, pp.310-357, https://doi.org/10.1037/0033-2909.98.2.310

[13] J. Y. Shin, K. S. Kim, The effects of university students' ego-resilience, family cohesion and social support on their mental health, Journal of Family Relations, (2019), Vol.24, No.2, pp.85-108. 
[14] E. Lee, B. K. Kim, A Convergence Study on Effects of Nutrition Knowledge, Dietary Habits, and Dietary Self-efficacy on Dietary, Journal of the Korea Convergence Society, (2020), Vol.11, No.2, pp.341-350.

[15] .J. W. Park, A Study to Development a Scale of Social Support, Yonsei University, Doctoral dissertation, (1985)

[16] Y. K. Hwang, A Study on Social-support Perceived by Adolescent Peer-group and Psychosical Maturity, Ewha University, Master`s thesis, (1996)

[17] H. Barnes, D. H. Olson, Parent-adolescent communication, University of Minnesota, (1982)

[18] H. Y. Min, The Relation between Juvenile Deliquency and Parent-adolescent Communication, Family Cohesion and Adaptability, Korean Journal of Child Studies, (1992), Vol.13, No.1, pp.112-124

[19] D. M. Garner, M. P. Olmsted, Y, Bohr, P. E. Garfinkel, The Eating Attitudes Test: Psychometric Features and Clinical Correlates, Psychological Medicine, (1982), Vol.12, No.4, pp.871-878, doi: 10.1017/s0033291700049163

[20] J. Choi, D. Ahn, J. Nam, Y. Cho, B. Choi, Reliability Testing of Eating Attitude Test for Korean Adolescents, Journal of the Korean Academy of Child and Adolescent Psychiatry, (1998), Vol.9, No.1, pp.91-97.

[21] H. Jang, H. Kang, A Study on the Relationship between Depression and Eating Disorders among College Students of Northern Gyeonggi-do, Korea, Journal of Health Informatics and Statistics, (2017), Vol.42, No.2, pp.108-115.

[22] S. Baek, J. Park, H. Kim, T., Kim, Eating Attitudes, Depression, Parent-child Interaction, and Family Function of Adolescent Girls, Journal of Korean Academy Psychiatric Mental Health Nursing, (2012), Vol.21, No.3, pp.176-187.

[23] K. C. Fragkos, C. C. Frangos, Assessing Eating Disorder Risk: The Pivotal Role of Achievement Anxiety, Depression and Female Gender in Non-Clinical Samples, Nutrients, (2013), Vol.5, No.3, pp.811-828, DOI:10.3390/nu5030811

[24] S. S. Kong, Impact of Eating Psychopathology, Obsessive-Compulsion and Depression on Self-Harm Behavior in Patients with Eating Disorders, Journal of Korean Academy of Nursing, (2009), Vol.39, No.4, pp.459-468.

[25] N. Horesh, E. Sommerfeld, M. Wolf, E. Zubery, G. Zalsman, Father - Daughter Relationship and the Severity of Eating Disorders, European Psychiatry, (2015), Vol.30, No.1, pp.114-120. 